\title{
Acervo Plástico y Documental María y Pablo O'Higgins, la necesidad de contar una experiencia
}

María Maricela Pérez García

Todos los niños mitifican su nacimiento. Es un rasgo universal. ¿Quieres conocer a alguien? ¿Su corazón, su mente, su alma? Pídele que te hable de cuando nació. Lo que te cuente no será la verdad: será una historia. Y nada es tan revelador como una historia. Vida Winter ${ }^{l}$."

\section{El inicio de una historia}

Quiero que sepan que no me ha gustado trabajar por las tardes, porque creo que al igual que el día, es el momento de aquietar el espíritu, pero la necesidad me llevó hacerlo varias veces. Así me miro en el Callejón de Xochicaltitla, en la Ciudad de México, frente al número 52, leyendo la placa pegada afuera de la Residencia Estudio María y Pablo O’Higgins.

Maricela ante la casa-estudio María y Pablo O'Higgins, 2019, Ciudad de México. Fotografía: Verónica Arenas Molina

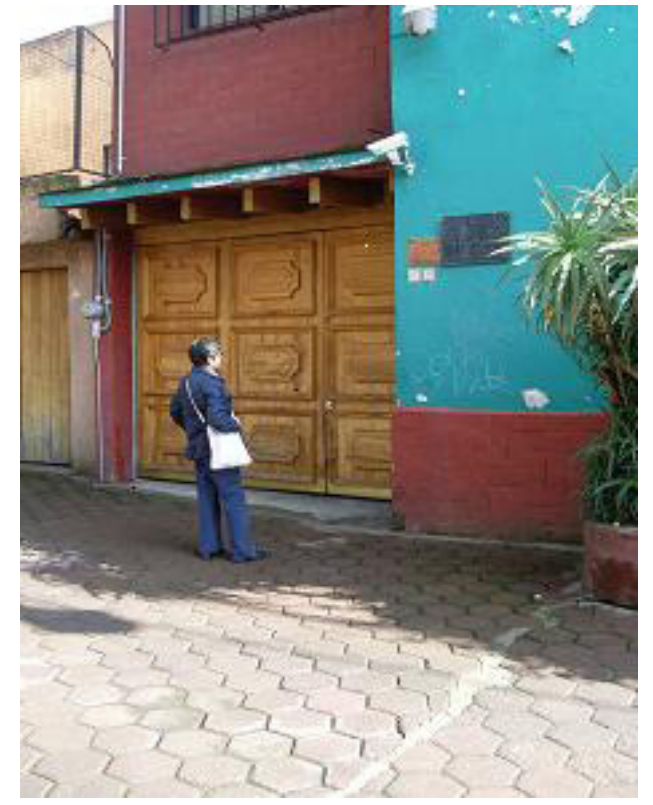

Eran las dieciséis horas del veintiocho de febrero de 1998, era una tarde tranquila y apacible de invierno, cuando me recibió la viuda de Pablo O'Higgins, la Señora María de Jesús de la Fuente Casas, ella aún con sus rasgos de belleza y porte, que la caracterizaban a sus 78 años de edad, en aquel tiempo. Observó mi forma de proceder y como toda una abogada la presentación y entrevista fueron precisas y breves, esto marcaría el inicio y el desarrollo de esta historia. Me invitó a subir al Estudio de Pablo O'Higgins y de ella, porque han de saber que también pintaba, fue cofundadora con Marco Cuellar de los jardines del arte en la ciudad de Monterrey. Además de fungir como abogada, hacía muchas actividades políticas y sociales de gran transcendencia histórica para México.

Al entrar y cruzar por el estudio tuve un impacto para mis sentidos el olor, que oscila en el ambiente, el color que esta por el suelo, paredes, mesas, repisas y el intercambio de miradas de tantos personajes plasmados en papel o lienzo, que en algún tiempo tuvieron vida. Si uno se adentra en ello, termina atrapado entre palabras, trazos y esbozos de lo que vivió y vio Pablo O'Higgins al hacer suyo a México acompañado de amigos y de su esposa María. Este impacto, fue algo que se tuvo que ir diluyendo a través del tiempo y paso a formar parte de mi vida.

${ }^{1}$ Personaje ficticio, coprotagonista de la novela: Setterfield, D. 2007. El cuento número trece. México, Lumen. 
Seguimos caminando y pasamos a la continuación del estudio. Ahí me indicó donde sería el lugar de trabajo e inició la prueba. Me proporcionó un dibujo de Pablo O'Higgins que saco de un mueble diseñado ex profeso, para guardar obra de arte enmarcada o sin enmarcar, y me pidió que lo describiera en unos formatos de inventario de obra ya diseñados por antiguos colaboradores. Se sentó frente a mí, observando cómo me conducía con la pieza de arte (manejo físico) y como reconocía la información y llenaba el formato. En ese momento todo lo estudiado en la biblioteca, previo a la entrevista, sobre Pablo O'Higgins se deshilvanó. Las ideas, venían fragmentadas y trataba de asirme de alguna de ellas, tuvo que aflorar la clase de anatomía de la preparatoria, para poder salir adelante en esta prueba. Recuerdo el dibujo era un fragmento del tarso y metatarso, un detalle del Mural "la maternidad y la asistencia social" realizado en 1946, que se encontraba en la Clínica No. 1 del Seguro Social, destruido por la remodelación del edificio. Mi proceder con la obra y el llenado de la ficha fue bien visto por la Señora María. Así, que a partir de ese día inicié el trabajo en este acervo.

\section{Un esbozo del trabajo}

Al principio asistía sólo los martes, subía al estudio en compañía de la Sra. María y trabajamos juntas en la identificación de dibujos y apuntes. Ella comenzaba a platicar de la pieza que estábamos describiendo o de alguna otra vivencia entre Pablo O'Higgins y ella. Al escucharla pensaba: "este testimonio debe de estar guardado, recogido o contenido en algún lugar de esta casa". Pero con el paso del tiempo esta idea se desvaneció, pues no hay ningún registro hasta la fecha. Esto me ha llevado a reflexionar: los archivos están adornados con la memoria oral y será necesario revestirla con la palabra escrita. La memoria que ahora está en crisis por tanta tecnología. Y quizás alguien cuestione esto. La memoria aún no ha sido suplida por el ordenador. A pesar de que estén descritos los documentos en las bases de datos, si yo no sé qué existe un documento determinado, tardaré en accesar a él. La experiencia me ha permitido

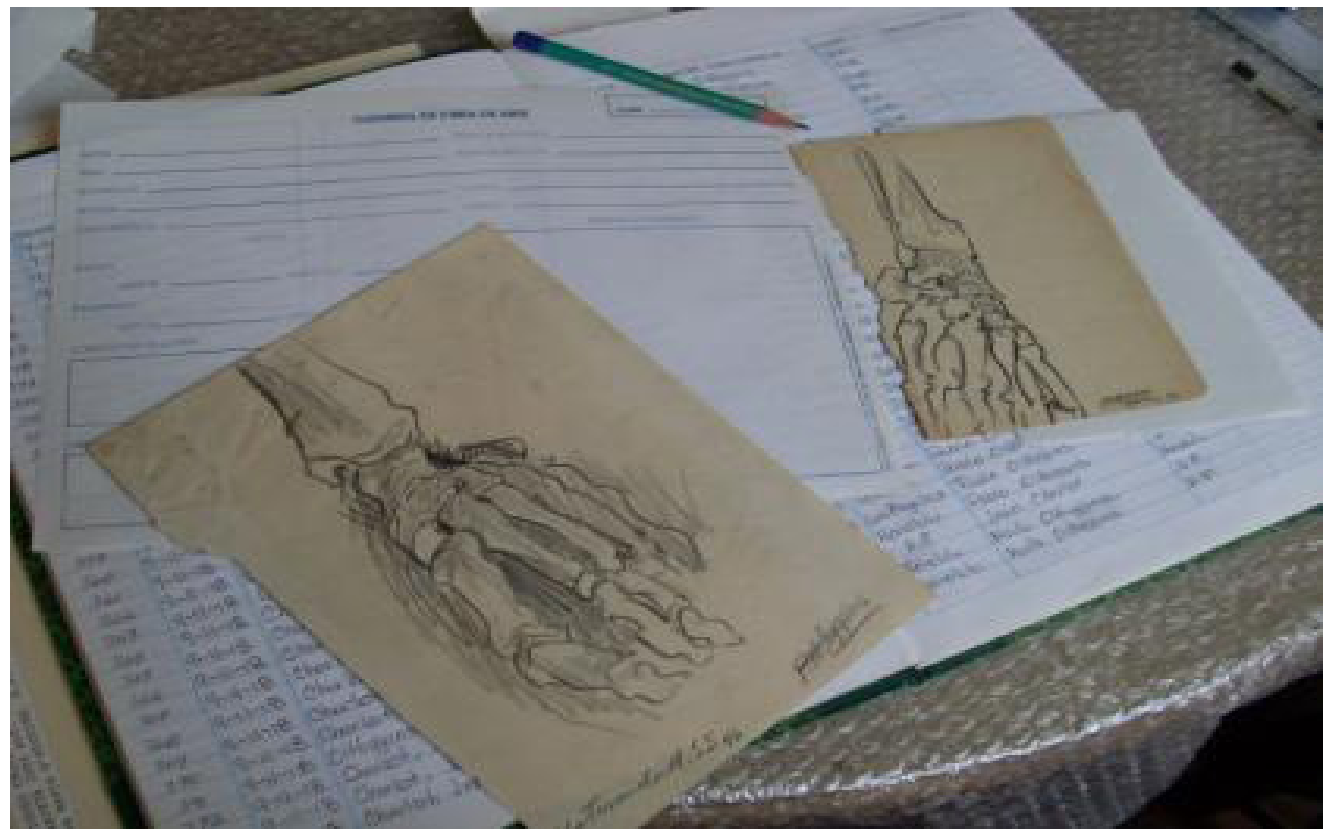

Trazo y metatarso, dibujos de Pablo O'Higgins para el Mural "la maternidad y la asistencia social" realizado en 1946, que se encontraba en la Clínica No. 1 del Seguro Social. 2019. Fotografía: María Maricela Pérez García 
jugar al memorama en los acervos cuando he tenido la oportunidad de conocerlos en la profundidad, en su alma, claro está que implica tiempo; el cual, actualmente, no hay mucho pues hay que aumentar las estadísticas.

En el proceso de creación de cada obra de arte, documento (cuando es contextualizado) o papel (para el generador) lleva una vivencia, acompañada de gestos, silencios, pausas, preguntas, meditaciones que dan cuerpo, argumento y sentido (Steiner, 2011), por lo que no se debe reducir a la descripción del soporte y su contenido toda esa fascinación.

Es como la fotografía que no captura con la profundidad del ojo humano, esa visión no es igual, así se tratara de describir lo más completo el documento siempre habrá algo que falte y es el contacto humano su interpretación y la necesidad vista o reflejada en ese registro. El mirar del catalogador no será la del estudioso o necesitado de la información, esto se ha tratado de solventar con la aplicación del código Descripción y Acceso a los Recursos (RDA), pero no en todas las instituciones lo hemos implementado, únicamente las grandes bibliotecas. Reconozco que los ordenadores son de gran ayuda y nos permiten tener el control documental y administrar sistemas complejos de información y en este caso de bienes patrimoniales de gran envergadura.

Regresando a la historia. Así empezamos a conocernos hasta lograr una confianza mutua. Un día en lugar de sentarnos a trabajar los dibujos, me pide que le ayude a abrir unas cajas y ver lo que resguarda un mueble gris. Con su mirar pregunta ¿cuál es tu opinión para organizar estos contenidos? Ella observa mi cara de asombro, de interrogantes, de alegría. Y se retira dejándome con el acertijo. El silencio y tranquilidad que hay en esa casa lleno mis oídos; lo que permitió que tomara las mejores decisiones. Primero sacar la vir- tud de la prudencia. Recuerdo que Santo Tomás de Aquino decía que la mejor manera de hacer las cosas es después de un tiempo de silencio, escucha, encanto, reflexión, diálogo, cuestionamiento y respuesta (Almeida, 2012). Así que tuve que analizar y conjugar la metodología de la bibliotecología, de la documentación, de la archivística y los conocimientos adquiridos de mis maestros-compañeros de trabajo de aquel entonces, quienes fueron los que conformaron el acervo primitivo del Cenidiap. Algunos de ellos ya fallecidos. Todo esto me ayudó hacer frente a esta labor.

$\mathrm{Al}$ ver que el trabajo aumentaba día con día, pues la Señora cada vez me señalaba donde había más documentación para trabajarla, pedí la colaboración de una amiga y compañera del Cenidiap, Verónica Arenas Molina. Y antes de abordar los grupos documentales y hacer la propuesta de trabajo nos dedicamos a saber más acerca de Pablo O’Higgins.

\section{Protagonistas}

Pablo O'Higgins nace en Utah en el año de 1904, estudió piano, dio su primer recital a los diez años de edad, como en su escuela no había maestro de composición, opta por estudiar en la Academia de Artes de San Diego, por muy poco tiempo. Estando en Guaymas, su madre le envía un ejemplar de la revista de "The Arts", donde aparece un reportaje sobre la obra mural de Diego Rivera en la escuela Nacional Preparatoria, le escribe a Rivera y es invitado por este a venir a México y a unirse a su grupo de ayudantes en los murales en la Secretaría de Educación Pública y en los de Chapingo. Perteneció a varias agrupaciones: Sindicato de Pintores, Escultores y Grabadores, Revolucionarios de México (1924-1928), Partido Comunista Mexicano (1927), Liga Intelectual Proletaria (1931), Liga de Escritores y Artistas Revolucionarios (1934), Taller 
de Gráfica Popular (1937), Sociedad para el Impulso de las Artes Plásticas (1948), Salón de la Plástica Mexicana (1949), Asamblea Nacional de Artistas Plásticos (1952). Participó en la Misiones culturales (1928-1929).

Realizó varios murales en edificios públicos de México y Estados Unidos:

1.- La explotación del trabajo infantil en las fábricas, los explotados contra los explotadores, y la rebelión contra la dominación del clero católico (1933). Primaria Escuela Emiliano Zapata.

2.- La lucha de los obreros contra los monopolios (1934-1936). Los murales del Mercado Abelardo Rodríguez.

3.- La lucha sindical (1936-1937). Talleres Gráficos de la Nación. UNAM.

4.- La Expropiación (1939-1940). Escuela Técnica Estado de Michoacán.

5.- La lucha contra la discriminación racial y la unidad obrera (1945). Sindicato Limpiadores de Quillas de Barco de Seattle.

6.- La maternidad y la asistencia social (1946). Clínica de Maternidad no. 1 del Seguro Social.

7.- La importancia de la educación (1949). Escuela Gabriel Ramos Millán.

8.- Construcción de un nuevo pueblo debido a la erupción del volcán Paricutín (1950). Escuela primaria de Caltzontzin, Michoacán.

9.- La invasión norteamericana de Veracruz (1950). Mural transportable.

10.-Solidaridad sindical (1952). Unión Internacional de Trabajadores Marítimos. Honolulu.
11.-Desde las primitivas labores agrícolas prehispánicas hasta el actual desarrollo industrial (1958-1959). Palacio Municipal de Poza Rica.

12.-Tenochtitlán libre (1960). Universidad Michoacana.

13.-Mercado interior indígena (1961). Banco Nacional de Comercio Exterior.

14.-Boda indígena en el pueblo de San Lorenzo, Paisaje Tarahumara y Dios del Fuego (1963-1964). Museo Nacional de Antropología.

15.-La defensa de la nación contra las invasiones extranjeras (proyecto mural) (1979). Obispado de Monterrey.

16.-Proyecto mural para la Universidad Agraria Antonio Narro en Coahuila (1980).

17.-Proyecto mural para la Universidad de Colima (1983).

Su trabajo de obra de caballete y gráfica es muy grande en cantidad y en temáticas que aborda. Colaboró con agrupaciones,

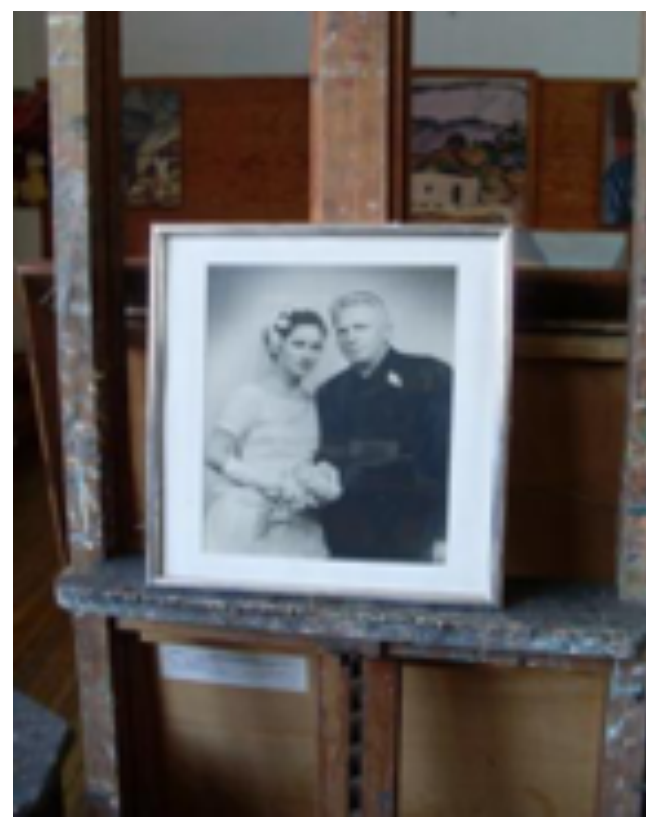

María y Pablo O'Higgins mayo de 1959 en la ciudad de Monterrey, 
asociaciones civiles, religiosas donando obra para ser subastada. Extensas son sus exposiciones individuales y colectivas, la primera fue en 1925 en San Francisco y la última en 2017 en la Ciudad de México en el Museo Mural Diego Rivera. (Reyes Palma, 2003)

La obra mural realizada en Poza Rica, Veracruz, fue muy importante y significativa para María y Pablo. Porque gracias a la técnica empleada de cerámica opaca tuvo que recurrir a una industria de cerámica establecida en Monterrey, además coincidió en que también fue a impartir un curso de pintura al fresco en la Universidad de Nuevo León en 1958. Es cuando se conocen y el 23 de mayo de 1959 contraen matrimonio. Ella tenía 38 años y él 55. Estuvieron juntos hasta el 16 de julio de 1983, fecha en que falleció el pintor. (Bravo, 2014).

\section{El Acervo}

El Acervo tienen dos principios: por el pintor Pablo O’Higgins (1904-1983) y por María de Jesús de la Fuente Casas (1920- ), su fusión fue en 1959, cuando contraen matrimonio. Se ha mantenido e incrementado por la labor de la Sra. María, y está conformado por una gran diversidad de documentos: catálogos de exposición (individuales y colectivos), invitaciones de exposición (individuales y colectivas), libros, revistas, periódicos, cartas, planos, diapositivas, fotografías, carteles, postales, folletos, hojas sueltas, volantes, videos, literatura gris, entre otros, todos ellos son materiales de difícil tratamiento físico, de análisis y de conservación, debido a su soporte y formato. Y la parte de obra de arte: se divide entre grandes secciones: Colección de Pablo O'Higgins: Conformada por obra de caballete (óleo, encáustica, acuarela, obra inconclusa y telas preparadas), gráfica (litografía, xilografía, linóleo, aguafuerte, piedras litográficas, clichés, láminas), dibujos, apuntes, proyectos de pintura mural y portafolios. Colección de María O'Higgins: Conformado por obra de caballete (óleo, acuarela) y gráfica (litografía). Colección de otros artistas: Conformada por obra de caballete (óleo, acuarela) y gráfica (linóleo, litografía, xilografía, serigrafía, carteles, entre otros).

Antes de abrir bolsas, cajas, envoltorios, se realizó un registro fotográfico, se entrevistó a la Sra. María y se explicó la metodología que se seguiría en el proceso informativo-documental (proceso de configuración del acervo, proceso de organización y proceso de difusión) (Martínez Comeche, 2002) partiendo de un diagnóstico para poder proponer la forma de abordar este patrimonio. Se hace un proyecto para formalizar el trabajo de organización pero necesitábamos una teoría y una metodología para explicar este trabajo de manera que lo comprendiera la dueña del acervo. Así que recurrimos a la Teoría General de Sistemas propuesta por Ludwig von Bertalanffy en 1937. En un sentido amplio el sistema puede ser concebido como un conjunto de elementos interrelacionados e interactivos que resaltan la unidad, es decir nada está aislado (García Cuadrado, 1995). El sistema está conformado por cuatro unidades menores llamada subsistemas que tiene a su vez una estructura propia de acuerdo a su función. Los subsistemas son: Administrativo, conservación, análisis documental y difusión.

La historia de la formación del acervo documental y plástico María y Pablo O'Higgins no es únicamente de estos dos protagonistas, de su saber, labor, desarrollo y pensar, es también, del acontecer de su entorno, del país, del encuentro con personajes, del reflejo de costumbres, quehaceres en distintas ramas de la vida del hombre y una continuidad del trabajo de otros organizadores del acervo. 
La cantidad del acervo ha aumentado desde 1998 a la fecha. Originalmente se encontraban 15 carpetas lefort con numeración romana (introducción, curriculum vitae, entrevistas, catálogos de obra, catálogos individuales, catálogos colectivos, venta de navidad, subastas, hemerografía, fotografía, fotografía personal, documentos personales, textos del artista, conclusiones y lista de coleccionistas) y 4 cajas de archivo.

La siguiente descripción muestra el trabajo cuantitativamente lo que se ha realizado, pero también es un reflejo cualitativo, ya que, para la organización de un acervo con estas características tan singulares, se necesitó de la maduración del conocimiento y del documentalista acerca de los objetos que estamos trabajando: de Obra son $140 \mathrm{ml}$., aproximadamente, acervo documental, $87.40 \mathrm{~m}$. lineales, aproximadamente, material del pintor: $17.48 \mathrm{ml}$., aproximadamente.

Por ejemplo estoy describiendo un catálogo de exposición colectivo, donde se expuso la obra "Hombre del siglo XX", debo saber si se reprodujo o se habló de ella en la colección de Publicaciones periódicas, si se generó documentación para el préstamo de obra en la Colección archivo administrativo, si hay algo en libros, en el expediente personal, en la libreta de registro de obra, en el acervo de obra de arte o en la lista de coleccionistas. Por lo que es necesario conocer la documentación, la obra y activar la memoria visual.

\section{El atardecer de una historia}

Como en toda historia hay algunas cosas so- brenaturales, lo que hace emocionante el trabajo. Ahora a sus 98 años, casi 99 en unos días (18 de octubre) a la Señora le gusta mucho platicar, afloran historias sorprendentes; discutir y pelear acerca de situaciones, pensamientos y costumbres y se puede llegar a un momento álgido, acalorado y ambas no sedemos, pero recurro a la virtud de la prudencia para ir suavizando la conversación y así terminar la jornada de trabajo con un rico sabor agridulce. No se avanza, pero eso nos ayuda a ambas.

El destino es incierto para este acervo, hay días en que el sol resplandece y parece que está solucionado, pero al regresar al otro día a trabajar ya está nublado y no hay nada. Ha habido varias propuestas, pero hasta ahí han llegado, pues se desatan tormentas por intereses personales, es decir, el egoísmo y avaricia se hacen presentes y frenan o alejan las buenas intenciones con sus autores. Actualmente el Instituto Nacional de Bellas Arte y Literatura está tratando de ayudar a la Sra. María y esperemos tenga esto buen fin para todos.

\section{Bosquejo de conclusión}

Que rescato de esta experiencia de vida hasta el día de hoy:

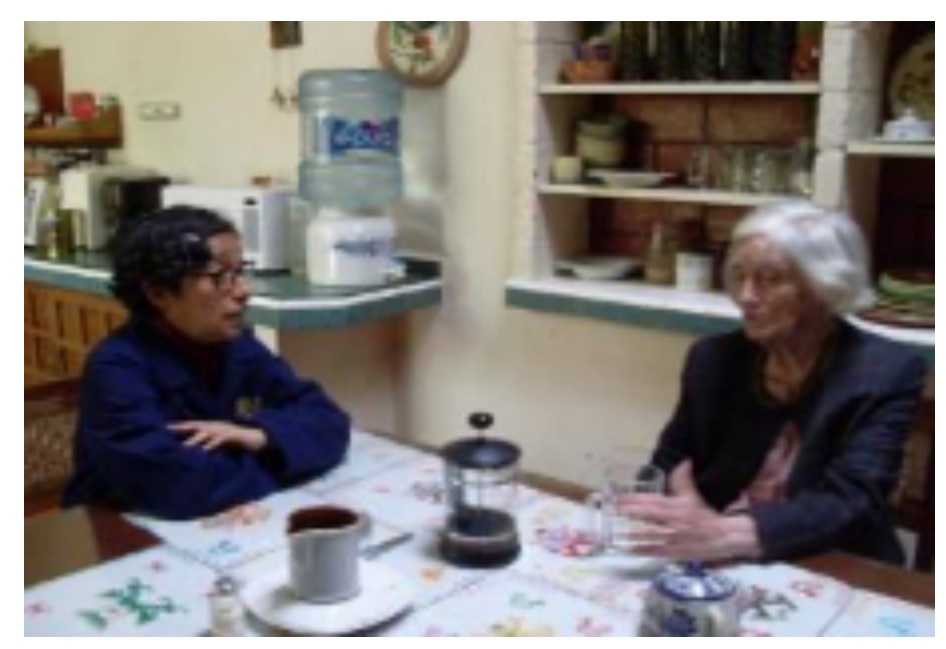

O'Higgins y Maricela conversando en la cocina Casa estudio María y Pablo O'Higgins en la Ciudad de México, 2019. Fotografía: Verónica Arenas Molina. 
María O'Higgins es quien se ha encargado de hacer de este acervo singular una forma de vida. Lo hace caminar por las constantes consultas por parte de ella y de los estudiosos. Los senderos trazados nos llevan a un camino sin final y que cada uno de los organizadores y consultores nos encargamos de dárselo.

Que independientemente de los conocimientos adquiridos en el área de bibliotecología, debemos saber conducirnos con moral o ética. Esto incluye el respeto a los personajes (personas vivas o muertas), respeto al lugar donde se trabaja (casa o institución) y respecto a uno mismo en nuestro desempeño y de la forma de ser ante este patrimonio artístico nacional.

Siguiendo con este caminar que es silencioso y que se forma poco a poco se puede llegar a dar como frutos la amistad, la ayuda mutua ya no es de intereses propios o egoísmo sino de comunión para el bien de todos.
El lugar que tienen los dos protagonistas, su significación histórica, ya se han encargado de hacerla los estudiosos, ya la han estructurado e interpretado desde su propia experiencia. Pero de quien realiza el trabajo de archivo, biblioteca, que es callado, lento, minucioso, detallado, actualmente se ve la necesidad de contarlo de hablarlo de volvernos protagonistas del quehacer documental y de su gran repercusión en la inserción de la memoria histórica de México en las artes plásticas

La otra historia que crece paralela a la de los protagonistas es nuestra repercusión en la historia de México. Cuando se logra concretar que pase a ser reconocido como patrimonio nacional, es tomar conciencia de la importancia de nuestra labor.

La historia narrada nunca estará completa, nuca se acabará llegará otro y la tendrá que continuar.

Gracias.

Ciudad de México a 29 de agosto de 2019.

\section{Trabajos citados}

Almeida, J. C. (2012). Letanias a nuestra señora, el sentido de cada invocación. Bueños Aires: Editorial Calaretiana.

Bravo, C. (2014). María de Jesús de la Fuente Casas de O’Higgins. Memoria, 10-13.

García Cuadrado, A. (1995). Notas sobre la teoría general de sistemas. Revista general de información y documentación, 197-213.

Martínez Comeche, J. A. (2002). El proceso informativo-documental. En J. López Yepes, Manual de ciencias de la documentación (págs. 25-31). Madrid: Pirámide.

Reyes Palma, F. (2003). Pablo O'Higgins. México: Fondo Editorial de la Plástica Mexicana.

Steiner, G. (2011). El silencio de los libros. Madrid: Siruela. 